\title{
Correspondence
}

\section{A Subversive Foray into Private Practice}

DeAR SIRS

I feel compelled to reply publicly to Professor Brandon's Conference Report (Bulletin, January 1987, 11, 23-24) on our recent Private Practice seminar. Referring to one of my colleagues as a "gamekeeper turned poacher" would be amusing on its own, (in fact, was the Professor there to poach?) but innuendoes such as ".... . speakers. . . shot their immaculate cuffs before casting their pearls...." betray a bias on the part of this eminent representative of the profession. Amusement aside, his Report is a vivid illustration of the sort of outdated dogmatism which pervades the NHS and serves to insulate it from fresh ideas.

The Professor's reporting style notwithstanding, (I failed to note at the event whether his cuffs were respectively frayed) he raises a number of excellent and timely questions about the need to examine carefully the relationship between the private sector and the NHS, some of which can be answered briefly.

Q: "Would private care benefit the NHS or the population at large? Is there any evidence of such benefit?"

A: With $5 \frac{1}{4}$ million private insurance subscribers and another 3 million paying fees from their own pockets, about 8 million Britons, or 15\%, make use of independent services to some degree. In perspective, this is equal to the catchment of two average Regional Health Authorities. The independent providers of service save the NHS and the Exchequer some $\$ 900$ million per year, or $\mathbf{f 1 0 0}$ in taxes per household. According to the Independent Hospital Group, a trade association, there are now over 25,000 beds in private facilities in this country, (only $5 \%$ of which, incidentally, are Americanmanaged) the majority of which are critically needed long-stay beds. The replacement cost for this sector of Britain's health system, at the $£ 30,500$ per bed cost the DHSS budgets for non-surgical beds, would cost the tax payers in the order of $\mathbf{1 8 0 0}$ million. The sector has become too big for Goliath to continue to ignore. One must agree with Professor Brandon's view that it is timely to study the interrelation between the two, largely segregated, systems. In the last decade a pluralistic health care system has evolved, without the two major components devoting much serious thought to their relationship.

Q: "The investment in staff time and hotel services of the private sector could never be replicated in the NHS, but is there any evidence of actual or potential harm to the services?"

A: First, we have not seen published any evidence of such presumed 'harm'. How can one service 'harm' another?
On the contrary, when monopolies are faced with competition, they respond positively, looking at ways of serving their clientele well enough to keep them from defecting to the upstarts. Can the Envy of the World be so blind that it does not see valid reasons for the bizarre spectable of $\mathbf{8}$ million Britons paying out-of-pocket for an essential service they can (in theory) get for free?

Secondly, the Professor errs when he assumes that the services of the private sector could never be replicated in the NHS. For example, we ourselves, in competition with other firms, have submitted a fixed-price tender to design, build, and commission (in 20 months) a 160-bed psychiatric hospital in Birmingham, modelled closely on our private hospitals' designs and services. Cost: approximately $£ 7$ million, embarrassingly half of the f14 million which the DHSS approved for its own design, and we can prove it would be cheaper to run, too. One might ask whether this type of innovation causes the NHS 'harm', when using such methods of contracting out the work could double the number of replacement beds Britain could afford. In another example, unrelated to psychiatry, we charge $\$ 81$ per treatment for haemodialysis in our units contracted to the NHS, versus a published cost of $£ 143$ in the Yorkshire RHA, and $£ 120$ to $£ 150$ in North East Thames. What would be the harmful effects in eliminating 1,000 deaths a year by contracting the service for just over half the current cost? Other independent groups queue to provide hip joint replacements, hernia repairs, lithotripter procedures, cataract operations and so on at prices (including the cost of starching expensive Harrodian cuffs) lower than many District Health Authorities can do the job for themselves.

Q: With reference to a secure unit contracted to the NHS, the Professor asks: 'With 49 beds and a charge of about $£ 35,000$ per patient per annum is this an economical solution? If an American company can run this at a profit, why can't the NHS?"

A: We understand that the daily charge at this unit is $f 110$. Hard NHS costs are difficult for us "gamekeepers turned poachers" to come by, but we do know that the comparable NHS pay bed costs $\$ 126$ per day in a provincial teaching hospital, and up to $£ 182$ in London. There is good cause to think that the DHAs which contract with these units (to my knowledge there are now three in Britain which accept 'medium secure' referals) are spending DHSS money prudently, and saving the NHS substantial capital expenditures to boot.

As to the second question, a treatise could be written, and in fact we are collecting field data for it. The prepublication answer is that entrepreneurs in any line reduce the provision of goods or services to their simplest 
elements, cost them carefully, find ways of cheapening production costs without cheapening the quality of the product (shoddy goods don't sell), and get on with it with a minimum of fuss. In the most efficient cases, private hospitals run as interlocking directorates of committees of one. Also, specialisation lowers costs by eliminating learning curves and minimising waste. The NHS already accepts this principle in the provision of goods, equipment, and peripheral services, or else it would not find it economical to purchase pharmaceuticals, X-ray equipment, printing, pest control, etc from others. If there is a valid intellectual or economic argument against contracting clinical services in the same way, then the NHS should apply the theory consistently: we would then have the NHS manufacturing its own pills, extruding plastic for its syringes, and perhaps weaving its own sheets and growing its own potatoes.

To conclude, having worked on psychiatric hospital development projects in countries over the last 18 years, I have learned that there is only one constant, a single universal principle which applies in our field: our collective egos insure that the cookbook for each new service gets written in a vacuum by a local committee, when we could often more easily solve health delivery problems by copying other peoples' successes and avoiding their failures. Health technology translates well everywhere in the world, perhaps because it is effectively sold by the fellows who make hardware, but inexplicably knowledge about what wins and loses in the low-tech end of our business does not translate well. Our collective record in innovative plagiarism on both sides of the Atlantic is appalling in such areas as administrative management, cost control techniques, social service provision, state-run insurance schemes, and designconstruction systems. Patients suffer needlessly as the result of our conceit. European and North American systems live in straightjackets of professional pride and xenophobia, altogether obsolete in an era of a global market for ideas.

JOHN C. Hughes Chairman

Community Psychiatric Centers

The Priory, London SW15

\section{DeAR SIRS}

Surely Professor Sydney Brandon is right (Bulletin, January $1987,11,23-24)$ in stating we must begin to address the many questions and issues arising from the explosive growth of private practice in health care, and in private practice in psychiatry in particular, and where better and more appropriate than within our own College?

I would be pleased to receive declarations of interest and support from colleagues, and with this support I will undertake to seek to establish a group for Private Practice in Psychiatry within the College structure.

J. H. HeNDERSON Medical Director

St Andrew's Hospital

Northampton NNI SDG
DeAr SIRS

As a Brit abroad may I comment on the amusing article by Professor Sydney Brandon entitled 'A Subversive Foray into Private Practice' (Bulletin, January 1987, 11, 23-24). He reflects on the need to study this issue in the UK but, in fact, he might look elsewhere.

Canada, like Australia and some European countries, went for prepaid insurance plans rather than state medicine, totally funded from taxation. Nevertheless, the medical and social services have become largely paid for by government. So the UK and Canada are now alike in that government pays for services. There the similarity stops. There is now virtually no private practice in Canada, since extra billing over the fee schedule was recently prohibited, although physicians have a spurious sense of doing private practice since they do fee-for-service medicine. The limitation is that patients must wait their turn to be seen and private practice presumably means jumping the queue by paying cash. As for the doctors, the academics have ceilings imposed by the Dean of Medicine's office while the nonacademics are constrained solely by time and the fee schedule. All doctors, even academics, make good salaries. The price is that Canada spends about $8.5 \%$ of the Gross National Product on health and the UK about $5 \%$, with similar mortality and morbidity rates.

Most doctors in Canada see patients regardless of status and job description. This keeps them in touch with the real world of doctor/patient relationships. (This obligation, however, prevents the academics from having many of those extensive lecture tours apparently available to their British counterparts.) Nevertheless, the British split into professors who cannot do private practice, permutations of salaries and capitation fees and private practice for the rich (or at least well insured) is seen as bewildering.

Modes of payment for medical services are different in advanced societies but it behoves us to ask why. Unfortunately (or fortunately), nothing is static and we see the British, buried in bureaucracy for $\mathbf{4 0}$ years, pursuing privatisation; while the Canadian doctors struggle with a system which controls the fee schedule, and therefore their income, while the public sees no need for private practice; whereas in the United States Diagnostic Related Groups and Health Maintenance Organisations, private hospitals and insurers and tough business-minded administrators have all contributed to a move from fee-for-service medicine to salaried practice.

So Professor Brandon should have a look at what is happening elsewhere. What he will find is a raucous debate about doctors' incomes, public expectations, government policy and business guidelines. All of which have little to do with the efficacy and efficiency of medical services.

Good luck!

M. R. EAstwood

University of Toronto; and

Clarke Institute of Psychiatry

250 College Street, Toronto

Ontario, Canada 